\title{
Learner-centered teaching in the college science classroom: a practical guide for teaching assistants, instructors, and professors
}

Margaret Dominguez, Shelby Vorndran

Margaret Z. Dominguez, Shelby Vorndran, "Learner-centered teaching in the college science classroom: a practical guide for teaching assistants, instructors, and professors," Proc. SPIE 9188, Optics Education and Outreach III, 918806 (15 September 2014); doi: 10.1117/12.2061523

EviE Event: SPIE Optical Engineering + Applications, 2014, San Diego, California, United States 


\title{
Learner-centered teaching in the college science classroom: a practical guide for teaching assistants, instructors, and professors Margaret Z. Dominguez*a, Shelby Vorndran ${ }^{\mathrm{a}}$ \\ ${ }^{a}$ College of Optical Sciences, The University of Arizona, Tucson, Arizona 85721, USA
}

\begin{abstract}
The Office of Instruction and Assessment at the University of Arizona currently offers a Certificate in College Teaching Program. The objective of this program is to develop the competencies necessary to teach effectively in higher education today, with an emphasis on learner-centered teaching. This type of teaching methodology has repeatedly shown to have superior effects compared to traditional teacher-centered approaches. The success of this approach has been proven in both short term and long term teaching scenarios. Students must actively participate in class, which allows for the development of depth of understanding, acquisition of critical thinking, and problem-solving skills. As optical science graduate students completing the teaching program certificate, we taught a recitation class for OPTI 370: Photonics and Lasers for two consecutive years. The recitation was an optional 1-hour long session to supplement the course lectures. This recitation received positive feedback and learner-centered teaching was shown to be a successful method for engaging students in science, specifically in optical sciences following an inquiry driven format. This paper is intended as a guide for interactive, multifaceted teaching, due to the fact that there are a variety of learning styles found in every classroom. The techniques outlined can be implemented in many formats: a full course, recitation session, office hours and tutoring. This guide is practical and includes only the most effective and efficient strategies learned while also addressing the challenges faced, such as formulating engaging questions, using wait time and encouraging shy students.
\end{abstract}

Keywords: learner-centered teaching, inquiry-driven classroom, optics education, wait time, large classrooms, vast curriculum, engaging questions

\section{INTRODUCTION}

For centuries the teaching style that has prevailed has been a lecturing teaching format. However, studies over the past decades have shown that while this may be the easiest teaching method, it is not the best learning method. A new technique that has proved effective is the student-centered (or learner-centered) teaching method, where the student retains newly acquired knowledge by almost immediately applying it. This method shifts the focus from the teacher to the learner ${ }^{1}$. Learner-centered methods are repeatedly shown to have a superior effect compared to traditional teachercentered approaches. The success of this approach has been proven in both short term and long term teaching scenarios. Since students have to actively participate in class, they remain engaged, which allows for the development of depth of understanding, acquisition of critical thinking, and problem-solving skills. However, learner-centered teaching does require a higher commitment on behalf of the instructor, obligating them to formulate questions appropriate for active learning. The teacher must not only be knowledgeable in the matter of subject to the taught, but also be creative in the challenges that are to be presented to the students. The extra effort pays off: when this technique is used correctly, positive attitudes are formed and students gain a higher level of confidence in their knowledge and skill sets.

To successfully implement this type of learning environment in a classroom, professional aid and instruction are often needed. The Office of Instruction and Assessment at the University of Arizona currently offers a Certificate ${ }^{2}$ in College Teaching Program (for more information see Appendix A). The objective of this program is to develop the competencies necessary to teach effectively in higher education today, with an emphasis on learner-centered teaching. The program is a 10-credit curriculum. Four of those credits require instructional practicum: an opportunity to practice techniques in the classroom and receive feedback. Margaret Dominguez and Shelby Vorndran, graduate students at the University of Arizona College of Optical Sciences, fulfilled this requirement by teaching a recitation class for OPTI 370 Photonics and Lasers for two consecutive years. The class was an optional 1-hour long session to supplement the course lectures.

*Further author information:

M. Z. D.: E-mail: mzd@email.arizona.edu, Telephone: 15203691906

S. V.: E-mail: shelbyv@email.arizona.com, Telephone: 12604149022

Optics Education and Outreach III, edited by G. Groot Gregory, Proc. of SPIE Vol. 9188,

918806 @ 2014 SPIE · CCC code: $0277-786 \mathrm{X} / 14 / \$ 18 \cdot$ doi: $10.1117 / 12.2061523$ 
This course provided a review of class material and served as a space to ask additional questions. Overall, the recitation received positive feedback and learner-centered teaching was shown to be a successful method for engaging students in science, specifically optical science.

This paper is intended as a guide for interactive, multifaceted teaching. The techniques outlined can be implemented in many formats: a full course, recitation session, office hours, and tutoring. This guide is meant to be practical. Only the most effective and efficient strategies are highlighted, and challenges will be addressed.

\section{WHAT IS LEARNER-CENTERED TEACHING?}

\subsection{Learner-centered teaching vs. traditional teaching}

In a traditional classroom, desks are lined up in rows facing forward. The teacher conveys information, sometimes using visual aids like a chalkboard or slideshow. Students are expected to listen, take notes, and demonstrate their knowledge after the lesson through homework assignments and exams. Although lecturing is the fastest way to move through course material, it is a one-way street because it lacks student feedback. Teachers may be moving at the wrong pace or have unclear explanations. Nonstop lecture can be overwhelming to students because there is no time provided to reflect on new concepts.

In learner-centered classrooms, student interaction is encouraged. Desks may be arranged in a large circle or in smaller sections facing each other to facilitate collaboration. Because students often form their own study groups after class, this teamwork structure is both familiar and energizing. Doing group work in class also allows the teacher to monitor and guide the process, keeping students on track. This technique is called cooperative learning. Similar to the structure found in a lab setting, it allows students to learn from their classmates while also requiring individual accountability ${ }^{3}$.

The learner-centered classroom is also active. The traditional, hour-long lecture should be broken into smaller sections (20 minutes or less). Breaks in the lecture are opportunities for student-teacher interaction, partner work, group work, or reflective writing. In the active learning approach, students solve problems, answer questions, either generated by themselves or the teacher, discuss, explain, debate, or simply brainstorm. Conclusions from these breakout sessions can be shared with the class and serve as an informal assessment: a snapshot of student understanding. Adjustments to the lesson plan can be made based on this insight. While "interruptions" to the lecture schedule may at first be seen as a misuse of time, the ability to customize one's instruction for maximum effectiveness is worth the effort in the long run. The learner-centered science classroom is driven by student curiosity. A technique called inductive learning dares students to go beyond their comfort zone and grow as problem-solvers. Students should occasionally be presented with problems which, given their current knowledge, they are not able to easily solve. The challenge presented motivates them to seek out and learn new material.

Finally, the learner-centered classroom gets students involved in the assessment process ${ }^{4}$. Often times, teachers score students' work using a rubric: a document that defines the criteria for a particular grade. However, in the traditional classroom the rubric is only seen by the teacher. It is utilized during the grading process, after students have turned in their work. In contrast, the learner-centered approach gets the classroom involved with the rubric from beginning to end. Students may even contribute to writing it. The rubric should be handed out before students begin their assignment. Students working in groups can use it to critique each other's work, and individual students can reflect on it before turning in their final draft. In this way, the assessment process can coincide with interactive teaching. Traditional learning is an approach that does not engage active learning, but instead discourages cooperation: for instance, grading on the curve can create an antagonistic environment.

\subsection{The inquiry-driven classroom}

To apply the learner-centered approach to teaching science, the concepts of cooperative, active, and inductive learning can be applied in the context of inquiry ${ }^{1}$. The goal for inquiry-based teaching is to foster an environment where students act as researchers in the classroom. A list of student qualities fostered in the inquiry-based classroom with specific examples for teachers is presented in the following table: 
Table 1. Appropriate teacher's role for inquiry-based student attribute.

\begin{tabular}{|c|c|}
\hline Students' Attributes & Teacher's Role \\
\hline $\begin{array}{l}\text { Show an interest and imagination in science } \\
\text { by acting as researchers or investigators and } \\
\text { viewing themselves as scientists. }\end{array}$ & $\begin{array}{l}\text { Hold students accountable to similar standards as scientists: they must actively } \\
\text { investigate ideas, produce ethical results, and give constructive criticism (Build } \\
\text { "peer review" into assignments). }\end{array}$ \\
\hline $\begin{array}{l}\text { Engage in diligent investigations from self- } \\
\text { generated questions. }\end{array}$ & $\begin{array}{l}\text { For a research assignment, give students an opportunity to choose their own idea } \\
\text { within a category (imaging systems, detectors, etc.) } \\
\text { Start class by asking students what they are most curious or confused about. } \\
\text { Use their question as an entry-point for discussion. }\end{array}$ \\
\hline $\begin{array}{l}\text { Reflect on and take responsibility for their } \\
\text { individual learning. }\end{array}$ & $\begin{array}{l}\text { Give the class a large-scale project, and give students individual assignments } \\
\text { within that project. } \\
\text { Assign textbook readings to students before class and hold a discussion of the } \\
\text { material in class. The reading could be the same for all students, or could be } \\
\text { split up among students to increase individual accountability. }\end{array}$ \\
\hline Work and communicate in thoughtful groups. & $\begin{array}{l}\text { Assign group projects, and allow time in the classroom for this work to take } \\
\text { place. } \\
\text { Ask a question in class, and give students the opportunity to discuss ideas and } \\
\text { come to a conclusion as a group. }\end{array}$ \\
\hline $\begin{array}{l}\text { Utilize higher-order thinking to solve } \\
\text { problems and make judgments about their } \\
\text { work. }\end{array}$ & $\begin{array}{l}\text { After grading a homework assignment, give students a chance to earn some } \\
\text { extra points back by rewriting an incorrect answer and explaining the original } \\
\text { error. }\end{array}$ \\
\hline $\begin{array}{l}\text { Consider skepticism and alternative models or } \\
\text { points of view. }\end{array}$ & $\begin{array}{l}\text { Present conflicting theories and current research debates in class and have } \\
\text { critical discussions of the ideas. }\end{array}$ \\
\hline $\begin{array}{l}\text { Make decisions as to how to communicate } \\
\text { their work. Demonstrate their science } \\
\text { understanding and abilities in a variety of } \\
\text { forms. }\end{array}$ & $\begin{array}{l}\text { Give students multiple presentation options: paper, poster, talk, slideshow, } \\
\text { demonstration, lecture, debate, animation, computer program, etc. }\end{array}$ \\
\hline $\begin{array}{l}\text { Use unbiased data and evidence to form } \\
\text { explanations. }\end{array}$ & $\begin{array}{l}\text { Encourage students to defend their conclusions with data, especially during lab } \\
\text { sessions. If a lab result does not follow the expectation, explain any flaws or } \\
\text { uncertainties in the measurements. }\end{array}$ \\
\hline $\begin{array}{l}\text { Act as "reflective friends" through peer } \\
\text { evaluation to seek other opinions and assess } \\
\text { the strengths and limitations of their work. }\end{array}$ & $\begin{array}{l}\text { Encourage a "peer review" environment. For example, give students an } \\
\text { opportunity to pair up and review a partner's assignment before turning it in. }\end{array}$ \\
\hline
\end{tabular}

\subsection{Recognizing and encouraging diversity of learning in science}

One of the reasons why traditional lecturing techniques are not as effective as learner-centered techniques is due to the variety of learners present in a class. Decades of research has been done on various learning styles ${ }^{5}$ and cognitive diversity. The accumulation of this work leads to ever increasing ways to categorize student learning. Some examples of dividing learning styles include big-picture/detail-oriented, conceptual/hands-on, and impulsive/methodical. Beyond these personality-based styles, diversity in the classroom includes broader contexts such as family environment, cultural background, and language abilities. A learner-centered science teacher should recognize the variety of student learning styles and respond by incorporating a range of teaching techniques. Diversity in teaching allows a teacher to reach out to each student while enhancing a broader skill set in all students.

What does diverse teaching look like? There are several roles the instructor can play in guiding students: 
- Motivator. Encourage students by supplying a driving question before and during an assignment. Provide relevance to students' work by relating it to their experience, interests, and future careers.

- Expert. The teacher is considered a source of knowledge. This style of teaching begins with traditional lecturing, but follows up on by giving advice, guidance, or clarification of concepts as students work.

- Coach. Give guided practice and feedback, while posing open-ended questions that allow students to discover things for themselves. Provide students with an environment to where they can experiment and fail safely.

Science has a reputation for being limited to one particular learning style, namely an analytical, logical, or methodical approach. While this attribute is essential to scientific knowledge, additional qualities enhance and improve the scientist's work. Creativity, social interaction, and big-picture thinking are essential. Creativity allows exploration and generation of possible directions in an investigation or engineering project. Social interaction is required in most laboratory work, whether between lab mates or among collaborative institutions. Finally, big-picture thinking allows one to put their work into a larger context. The ability to move back and forth between holistic understanding of a concept and step-by-step knowledge of each detail is one of the most valuable higher-order abilities to foster in a student of science.

A learner-centered teacher should also affect students' learning style in ways that enhance their abilities. For scientific work, the teacher can foster a self-directed and motivated attitude, build comfort with hands-on activity, encourage good note-taking and attention to detail, and demand a critical eye in the pursuit of evidence.

\section{CHALLENGES WHEN IMPLEMENTING LEARNER-CENTERED TEACHING}

\subsection{Asking engaging questions and using wait time}

The goal in asking a question out loud to a class is not to hear one student give the correct answer first. Rather, the goal is to get all students thinking about the question. There are several ways to do this. Ask the question first before calling on a particular student. Give students extensive wait time $e^{6}$ : Stand in silence for at least 5-10 seconds. It is natural for a teacher to get uncomfortable if students do not immediately raise their hands. However, pausing for a significant amount of time shows students that you are serious about them answering the question. It also allows students to think without rushing. Do not give in to the temptation to call on the first student that raises their hand. This is problematic because other students will disengage if a few eager students consistently answer the questions for them. This practice also forces the conversation into pace of the fastest learner, which makes it harder for other students to participate as the discussion progresses. To show an expectation of participation say, "Raise your hand when you can tell me...[question]." If students still hold back, follow up with "I only see a few hands...I need to see more!" to increase the pressure. Finally, if a question is especially challenging to students, break it down into smaller sub questions. Guide the students to the answer with lead-in questions that provide hints to the larger solution. Leading a discussion session is quite challenging to a teacher because it involves such a high level of interaction and improvisation. Mastering this technique is incredibly worthwhile, though. Discussion-based learning can occur in many contexts, from one-on-one office hour interaction to recitation sessions to post-lab discussions. In any case, the students will benefit from direct and personalized instruction, and the teacher will benefit from the level of insight to student understanding the discussion provides.

\subsection{Getting shy students involved}

If students are not eager to participate out loud, it does not necessarily mean that they are not engaged or are not understanding. Speaking in front of the classroom is difficult for shy students. To keep everyone involved, ask students to write their answer down or discuss it with their neighbor. This gives shy students an opportunity to practice their wording and gain confidence in their answers. The teacher could walk around the classroom, notice a student's written answer, and say "That is a useful perspective - I will call on you in a few minutes to share your answer." Doing this serves two purposes: it prepares the student to speak out loud, and it pre-validates their answer as being correct. If shy students gain confidence through these supportive speaking opportunities, they may push themselves to participate more overtly in future class discussions. Encouraging shy students to share their perspective as students is incredibly important - early encouragement will help them assert themselves in the future. Confidence is essential for job interviews, professional networking, teamwork/collaborations, and research presentations. 
It is important to remember that there will always be a few students who will remain shy. However, we must also remember that in a traditional lecture approach, $5 \%$ of the students (if that many) are actively involved and $95 \%$ are not. If interactive teaching exercises can do anything to modify those percentages, you are already ahead of the game.

\subsection{Too much material, too little time}

One of the drives for following a customary lecture teaching setting is the fact that there is a lot of material that needs to be taught in a specific, and most often short, time frame ${ }^{7}$. Of course, it is possible to project on a screen all the course material indicated in the syllabus in a short time frame, going through several book chapters of text in a month. The issue lies on the fact that this action does not allow for the students to learn, but just simply to observe a lot of text in a short time frame. Imagine how different the perception of the student would be if instead of only reading and making an exact replica of the text on the board into their notebooks, they had to engage in one or two quick active learning exercises, either by working individually or in small teams? This process would without a doubt slow things down and the syllabus would most likely not be completely covered, but the students would become more comfortable with the material presented.

Some active learning exercises include answering questions, starting problem solutions, filling in missing steps in derivations, brainstorming, formulating questions about material just presented, summarizing or even quizzes. A quick way to get all of the students to participate, even the shy ones, is to ask a few multiple choice questions. All students should quietly answer by a show of hand. The multiple choices are associated with a number, and the student would indicate the answer by holding up that number of fingers for the professor to see or writing it down on a piece of paper and showing that instead. These types of exercises take just a short break from the lecture, and will energize and keep the students focused and awake.

\subsection{Addressing large classrooms}

One of the concerns when dealing with active learning methods is how to properly use them when faced with large classrooms. Do active learning methods work in large classes? The answer is yes ${ }^{6}$.

Large classrooms are a challenging setting to implement interactive teaching: the professor may not able to make eye contact with everyone or even answer all of the students' questions. Shy students can be left behind even more so in larger classrooms. The key is to break up a large group into smaller groups that can interact, ask and answer questions. In this environment, even shy students are more likely to participate and feel less foolish. However, this may take time. The first time you assign group activity, the introverts in the class may pull back and try to avoid participating. The best thing to do is to simply walk over and remind the group that they are supposed to be working together. Once they realize that you are aware of their actions, they will be less likely to continue to pull back and after a few of these exercises it will feel more natural.

Some alternatives to posing questions to a large audience after a lecture and enduring a few long seconds of silence, are activities that Professor Richard M. Felder, Professor Emeritus of Chemical Engineering at North Carolina State University ${ }^{8}$, has proposed. His strategy is to assign a task and give the class a couple of minutes to work on it in groups of three to five. For example:

- Sketch a plot of what the problem solution should look like.

- Give several reasons why you might need or want to know the solution.

- What's the next step?

- What's wrong with what I just wrote?

- How could I check this solution?

- What question do you have about what we just did?

- Suppose I run some measurements in the laboratory and the results do not agree with the formula I just derived. Think of as many reasons as you can for the discrepancy.

- What variations of this problem might I put on the next test? 
The last two questions can be particularly engaging and instructive. More standard questions like 'Are there any questions?' or 'Did you understand what I just wrote/said?' tend to shut students down because they are broad and require a simple yes/no answer. The alternative questions listed are much more engaging: they are precise enough to generate specific answers, but open-ended enough to spark curiosity and generate critical thinking. By implementing a couple of these in a class, the students will be stimulated and will be more likely to pay attention the entire period. Keep in mind that there exercises can also be used during office hours.

Finally some additional specific examples that can be useful when practicing learner-centered teaching, in both large and small groups, such as specific formatted activities can be found in Appendix B.

\section{CASE STUDY: OPTI 370}

The motivation behind the creation of the course OPTI 370: Lasers and Photonics recitation 1 and 2 (junior level class) in the College of Optical Sciences at the University of Arizona was the need to meet the teaching requirement needed to complete the 10 credit College Teaching Certificate Program. [See Appendix A for program details] We selected this specific optics course after reviewing the list of courses offered as part of the undergraduate program in the college. We felt the most comfortable with the class material and the Professor teaching this class was enthusiastic about having us teach a recitation. The class, both times, was one hour long. Student attendance had no impact on their grades other than the knowledge of the material learned.

\subsection{Learner-centered teaching techniques applied in the OPTI 370 classroom}

The recitation course was observed by visitors throughout the semester. Various students from the Certificate in College Teaching program would sit in on the class and document their observations. The results are summarized in the following sections, which serve to validate the learner-centered approach and give specific examples of how to implement it.

\subsubsection{Creating a comfortable and interactive environment}

We created a consistent outline for the class in a lesson plan that started with a statement of objectives (goals) for the day, followed by an interactive lecture, followed by a question/answer session on class material and homework problems. The class seemed to feel comfortable with this structure, which gave us a sense of rapport with the students.

We also communicated frequently with the course instructor to make sure the material we taught was related to the curriculum and up-to-date with the lecture schedule. This communication allowed us to support the students by giving them relevant information. Because the course was also built around student requests, we built a large amount of time for student questions during the recitation period. We made sure, even during lectures, that interaction was a two-way street. The atmosphere felt relaxed yet authoritative. The class seemed comfortable asking questions and talking with us. Several students would stay after class for follow-up conversations. Voluntary interaction like this showed that we were approachable and students were comfortable speaking up.

\subsubsection{Customizing the curriculum}

Keeping the course relevant to student knowledge and interests is a basic tenet of learner-centered teaching. Before the semester began, we sent an email to all students asking for topics of interest. The course syllabus was attached. This served as a pre-assessment: it gave us an idea of what students already knew and alerted us to what areas were challenging. Based in the response, we tailored our lesson plans to go quickly over review topics and spend more time on tricky concepts. A small pre-assessment was also conducted at the beginning of every class by asking students if they had any conceptual questions from that week's material. At the end of each recitation, we would ask students to send an email if any future questions arose. Those topics would be addressed at the next session.

To keep students motivated, we provided a rationale for each step of our instruction. For example, Margaret would say "We are going to cover temporal coherence and coherence length because some of you expressed that you were not completely clear on this topic. We also talked to the instructor and he wanted to make sure you knew this. Many of you said in the initial assessment that you wanted a more detailed explanation." The research and technological applications of concepts were also highlighted to make the material relevant. Shelby talked about how some concepts were used in her research on holography. Margaret explained why some of the laser calculations were important in the real world, "In most optics related jobs, you'll have to run this kind of quick analysis, so you'll want to make sure you understand how to do it." 


\subsubsection{Helping students think explicitly}

Our lesson plan always included a question/answer session on homework problems. Rather than giving an answer or going through the problem ourselves, we would always call on the student asking the question to come up to the board and work on it. We would tell the student to get through as much of the problem as possible, and then tell us what needed clarification. This process gave the student (and the audience) a chance to reinforce what they already knew and put the problem into their own words. Often times, other students would come up to the board to assist the student. The process was explicit and broken down into basic steps. Working on a problem in front of the class allows each step to be analyzed and agreed upon, ensuring that most students are following the work from start to finish. Errors sometimes occurred along the way, but ultimately a deeper understanding was found by working through the mistakes.

\subsubsection{Addressing multiple modes of learning}

Our lectures often involved visual aids, computer simulations, or demonstrations. For example, Shelby would draw graphs of a laser's gain spectrum, asking students to describe the relationships illustrated. A computer program animating polarization was used for visualization. Margaret played a video that dramatized an application of polarization optics. Shelby brought in a calcite crystal to demonstrate birefringence. All of these examples helped to anchor students' book knowledge to a more tangible object or graphical relationship.

\subsubsection{Utilizing wait time}

Margaret was successful in implementing wait time. During one of the class periods she asked, "What are three types of photon transitions?" and waited 10 seconds. Even though there was initial silence, on average by second eight a student would respond. We used wait time during the question and answer session as well. After a homework problem was completed on the board, we would wait until all students finished taking notes and gave us cues that they understood the final answer.

\section{CONCLUSIONS}

In this work, learner-centered teaching has been defined and compared to traditional methods. Constant attention to student comprehension is vital, and the variety of learning styles found in the classroom requires a multifaceted approach to instruction. The learner-centered technique was more specifically applied to the science curriculum by emphasizing an inquiry-driven format. Common challenges to implementing learner-centered teaching were addressed. These struggles include formulating engaging questions, using wait time, encouraging shy students, covering a vast curriculum, and reaching out to large classrooms.

Lastly, an example of learner-centered teaching was described. The OPTI 370 recitation session was successful overall, especially from the students' perspective. At the end of the first recitation term we passed out teacher evaluation forms which were filled anonymously. The student's feedback was encouraging and showed the benefit of implementing learner-centered teaching. Some examples of student comments were: "They really solidified my understanding of the material", "I definitely feel that attending these really helped me be successful in this class", "This was a great review session and resource for our class. Those that attended seemed much more equipped to do the homework and tests", "Shelby and Margaret have done a great job during the recitation. I feel that I understand the subject more because of them. I probably would not be doing as well in class without them. They have been so nice and extremely helpful", and "I wish all courses had something like this."

\section{REFERENCES}

[1] Blumberg, Phyllis. Implementing learning centered approaches in your teaching. Retrieved April 20, 2013, from University of the Sciences Learner Centered teaching: http://www.usciences.edu/teaching/LearnerCentered/implementing\%20lct.pdf. 2008.

[2] Certificate in college teaching program. 18 March 2010. 20 April 2013. <http://oia.arizona.edu/project/certificatecollege-teaching-program>.

[3] Barkley, Elizabeth F; Cross, Patricia K. and Howell, Claire. Collaborative learning techniques. San Francisco: John Wiley \& Sons, 2005.

[4] Angelo, Thomas A. and Cross, Patricia K. Classroom assessment techniques: A handbook for college teachers. San Francisco: John Wiley \& Sons, 1993. 
[5] Felder, R. M. and Brent, R. "Understanding Student Differences." 2005. Resources in Science and Engineering education. 20 April

2013.

$<$ http://www4.ncsu.edu/unity/lockers/users/f/felder/public/Papers/Understanding_Differences.pdf $>$.

[6] Rowe, Mary B. "Wait time: slowing down may be a way of speeding up! ." Journal of Teacher Education 1986 vol. 37 no. 1 43-50."

[7] Felder, R. M. and Brent, R. "Active learning vs. covering the syllabus." 1999. Resources in science and Engineering education. 20 April 2013. <http://www4.ncsu.edu/unity/lockers/users/f/felder/public/Columns/FAQs-2.html>.

[8] Felder, R. M. "How about a quick one?" 1992. Resources in Science and Engineering education. 20 April 2013. $<$ http://www4.ncsu.edu/unity/lockers/users/f/felder/public/Columns/Quickone.html>.

[9] Llewellyn, Douglas J. Inquire Within: Implementing Inquiry-Based Science Standards. Thousand Oaks: Corwin Press, 2002.

[10] Andrade, Heidi G. Teaching with Rubrics: The Good, the Bad, and the Ugly. College Teaching, 2005.

[11] Cassidy, Simon. "Learning styles: An overview of theories, models, and measures." Educational Psychology (2004): 419-499.

[12] Dees, David M. "Peer review of teaching: A transactional process." 37th ISETL Annual Conference. 2007.

[13]Felder, R. M. and Brent, R. "Active learning: an introduction." August 2009. Richard Felder's home page resources in science and engineering education. 20 April 2013. $<$ http://www4.ncsu.edu/unity/lockers/users/f/felder/public/Papers/ALpaper(ASQ).pdf $>$.

[14] —. "Student-centered teaching and learning." n.d. Resources in Science and Engineering education. 20 April 2013. $<$ http://www4.ncsu.edu/unity/lockers/users/f/felder/public/Student-Centered.html >.

[15]Kolb, D. "Experiential learning: experience as the source of learning and development." 31 May 2006. Regis University adult learning. 20 April 2013. < http://academic.regis.edu/ed205/kolb.pdf $>$.

[16] —. Teaching high school science through inquiry: A case study approach. Thousand Oaks: Corwin Press, 2004.

[17] Moreno, A and Peña, R. "Optics teaching: new contents and methods." Sixth International Conference on Education and Training in Optics and Photonics. SPIE, 2000. 6.

[18] Pompea, Stephen and Stepp, L. "Great ideas for teaching optics." SPIE. SPIE, 2011. 5.

[19] Timpson, W. M. "Teaching and performing: Ideas for energizing your classes." The Lecture. 1997.

[20] Weimer, Maryellen. Learner- centered teaching: five key changes to practice. San Francisco: John Wiley \& Sons, 2002. 


\section{Appendix A: Certificate in college teaching}

The purpose of the Certificate in College Teaching is to provide students with opportunities to develop understanding and skills useful in their current and future careers as college level instructors. The program consists of a series of courses that provide foundational information and develop the competencies necessary to teach effectively in higher education today. Through an approach which focuses on theory into practice post baccalaureate students are prepared to become outstanding teaching professionals.

This program is a 10-credit curriculum. 3 of these credits require the completion of IA 697a Learner-Centered Teaching. This interdisciplinary graduate-level course has been designed to create a learning community to explore a variety of pedagogical perspectives pertaining to the theory and practice of learner-centered teaching (face-to-face and online formats) in higher education.

Four out of the ten required credits entailed the completion of the class IA 694a Instructional Practicum. This experiential course was the capstone course for the certificate which required working with a faculty development supervisor while teaching a semester long course. Throughout this experience the learner-centered instruction in the classroom was implemented. The practicum requirements included the creation and submission of instructional design plans for each class session; submission of critical self-reflective essays assessing the instruction for some class sessions; be observed by at least one content expert who then wrote a critical report with observations; be observed by at least two peers from the 694a cohort who then wrote a report; have one class videotaped and write a follow-up critical selfanalysis based on the video review; and finally completed a formative or summative teaching portfolio. The last 3 credits are completed through an elective coursework from an approved list or may be an new course, such as an independent study, which must be previously approved.

\section{Appendix B: Lerner-Centered teaching formats}

From the paper ‘Active learning: an introduction’ from Richard M. Felder and Rebecca Brent.

1. Tell the students to organize themselves into groups of 2-4 and randomly appoint a recorder in each group if writing will be required (e.g., the one born closest to the classroom, or the one farthest to your right, or the one who woke up earliest that morning,...). Alternatively, tell the groups to appoint their own recorders, preferably someone who has not yet recorded that day.

2. Pose a challenging question or problem and allow enough time for most groups to either finish or make reasonable progress toward finishing. The time you give them should normally be between 15 seconds and three minutes. If they will need much more time than that, break the problem into several steps and treat each step as a separate activity.

3. Call on several individuals or groups to share their responses, and ask for volunteers if the complete response you are looking for is not forthcoming. Then, discuss the responses or simply move on with your planned lecture.

There are many variations for this approach. Here are three particularly effective ones:

- Think-pair-share. Pose the problem and have students work on it individually for a short time; then have them form pairs and reconcile to improve their solutions; and finally call on several individuals or pairs to share their responses. This structure takes a bit more time than a simple group activity, but it includes individual thinking and so leads to greater learning.

- Concept tests. Ask a multiple-choice question about a course-related concept, with distractors (incorrect responses) that reflect common student misconceptions. Have the students respond using personal response systems ("clickers") and display a histogram of the responses. If clickers aren't available and the class isn't huge, have the students hold up cards with their chosen responses in large letters and scan the room to estimate the response distribution. Then, have the students get into pairs and try to reconcile their responses and vote again. Finally, call on some of them to explain why they responded as they did and then discuss why the correct response is correct and the distractors are not.

- Thinking-aloud pair problem solving. This is a powerful technique for helping students work through and understand a problem solution, case analysis, or text interpretation or translation. Have the students get into 
pairs and designate one pair member as the explainer and the other one as the questioner. Give the explainers a minute or two to explain the problem statement line by line (or explain the first paragraph of the case history or interpret or translate the first paragraph of the text) to their partners, and tell the questioners to ask questions when explanations are unclear or incomplete and to give hints when necessary. Stop the students after the allotted time and call on several individuals to explain things to you. Once you get a satisfactory explanation, have the pairs reverse roles and continue with the next part of the problem solution or case analysis or text interpretation or translation. Proceed in this manner until the exercise is complete. In the end, your students will understand the exercise material to an extent that no other instructional technique we know of can match. 